\title{
Hydrodynamic Friction of Viscosity-Modified Oils in a Journal Bearing Machine
}

\author{
Sorin-Cristian Vladescu ${ }^{1} \cdot$ Nigel Marx $^{1} \cdot$ Luis Fernández ${ }^{2} \cdot$ Francisco Barceló $^{2} \cdot$ Hugh Spikes $^{1}$ (I)
}

Received: 24 July 2018 / Accepted: 27 August 2018 / Published online: 6 September 2018

(c) The Author(s) 2018

\begin{abstract}
The friction properties of a range of viscosity modifier-containing oils in an engine bearing have been studied in the hydrodynamic regime using a combined experimental and modelling approach. The viscometric properties of these oils were previously measured and single equations derived to describe how their viscosities vary with temperature and shear rate (Marx et al. Tribol Lett 66:92, 2018). A journal bearing machine has been used to measure the friction properties of the test oils at various oil supply temperatures, while simultaneously measuring bearing temperature using an embedded thermocouple. This shows the importance of taking account of thermal response in journal bearings since the operating oil film temperature is often considerably higher than the oil supply temperature. For Newtonian oils, friction coefficient measurements made over a wide range of speeds, loads and oil supply temperatures collapse onto a single Stribeck curve when the viscosity used in determining the Stribeck number is based on an effective oil film temperature. Journal bearing machine measurements on VM-containing oils show that these give lower friction than a Newtonian reference oil. A thermo-hydrodynamic model incorporating shear thinning has been used to explore further the frictional properties of the VM-containing oils. These confirm the findings of the journal bearing experiments and show that two key factors determine the friction of the engine bearing; (i) the low shear rate viscosity of the oil at the effective bearing temperature and (ii) the extent to which the blend shear thins at the high shear rate present in the bearing.
\end{abstract}

Keywords Friction $\cdot$ Engine bearing $\cdot$ Viscosity modifier $\cdot$ Viscosity index improver $\cdot$ Shear thinning $\cdot$ Hydrodynamic lubrication

\section{Introduction}

In previous work, the temporary shear thinning behaviour of lubricant blends containing various commercial viscosity modifier additives (VMs) was measured over a wide shear rate range at several temperatures [1]. It was found that for all but one of the VMs, the viscosity of a given blend at all shear rates and temperatures could be described by a single equation based on time-temperature superposition. The resulting shear thinning equations were then used to explore the impact of the VMs on plain bearing friction using an isothermal, 3D hydrodynamic lubrication model [2]. This showed that VMs can reduce friction in two ways,
Hugh Spikes
h.spikes@imperial.ac.uk
Imperial College London, London, UK
Repsol Technology Centre, Madrid, Spain

by increasing viscosity index, leading to a low viscosity at low temperatures, and via shear thinning which reduces effective viscosity in high sliding speed, high shear rate lubricated contact conditions [2].

The current paper describes a combined experimental and modelling study of the impact of temporary shear thinning of VM blends on the friction of a plain journal bearing. A journal bearing machine (JBM) supplied by PCS Instruments, Acton, UK, is used to measure the hydrodynamic friction of a steadily loaded engine bearing, lubricated by some of the same VM blends characterised previously [1]. Friction is measured over a range of applied speeds, loads and oil supply temperatures.

In practice, plain journal bearings experience substantial thermal effects during operation so that their oil film temperature is usually considerably higher than the oil supply temperature, and it is essential to take this into account when interpreting bearing friction measurements. To address this, the temperature of the bearing is monitored 
using thermocouples. Alongside this, a 3D, thermal, hydrodynamic lubrication model of the bearing is employed to explore aspects of the thermal behaviour of the bearing not amenable to direct measurement. This allows JBM friction measurements to be compared with predicted friction for the VM blends studied, and thus to confirm experimentally the contribution of VMs to reducing hydrodynamic friction.

\section{Background}

Up to the mid-1970s, the temporary shear thinning behaviour of VM-containing engine oils was generally considered undesirable since it led to reduced hydrodynamic film thickness and thus the possibility of increased engine wear [3]. It was then noted that multigrade engine oils gave lower friction and thus better fuel economy than single grade oils of the same summer grade and that this arose at least in part from the shear thinning properties of VM polymercontaining oils [4]. In recent years, the ability of VMs to confer temporary shear thinning response and thus reduce hydrodynamic friction has become an important tool in the formulation of fuel-efficient engine oils [5, 6].

Until quite recently, one limitation in the study of the impact of temporary shear thinning on friction was that it was not possible to measure viscosities at shear rates above about $10^{6} \mathrm{~s}^{-1}$, whereas the shear rates present in actual engine components can considerably exceed this value [7]. As demonstrated in a recent paper by the authors, this issue has now been addressed with the development of the ultrashear viscometer (USV) that is able to reach $10^{7} \mathrm{~s}^{-1}$ without significant shear heating, enabling the development of reliable, isothermal viscosity-shear rate flow curves [1]. Using the USV, Warren et al. measured the viscosities of various model and formulated VM-containing oils up to high shear rate and compared these with film thickness and friction measurements in two journal bearing machines [8]. In most cases, the presence of shear thinning led to a reduction in friction compared to a base oil of comparable viscosity.

In principle, it should be straightforward to determine the impact of lubricant shear thinning on the friction of lubricated components such as plain bearings by solution of the relevant hydrodynamic lubrication equations in conjunction with a viscosity-shear rate relationship. However in practice, there are a number of problems. As well as the difficulty of measuring viscosity at very high shear rates, a major issue is that considerable energy dissipation due to fluid film shear occurs in plain journal bearings. This means that hydrodynamic analysis should incorporate both shear thinning and thermal effects and this requires a mathematical description of the dependence of lubricant viscosity on both shear rate and temperature, as well as a thermal model of the whole bearing. Another problem is the possibility, especially with low viscosity lubricants, of components operating in mixed lubrication, with a significant friction contribution from asperity contact. Yet another issue, which will be discussed later in this paper, concerns the extent to which the lubricant fills the bearing gap in the inactive, ambient pressure zone.

A number of studies have attempted to address some of the above issues. Taylor has measured the shear thinning curves of two formulated engine oils and employed fitted Cross shear thinning equations to explore the impact of shear thinning on friction using an isoviscous, short bearing model [7]. Ferron et al. have modelled the full thermal behaviour of hydrodynamic bearings to explore the impact of shear heating and lubricant viscosity on bearing temperature and eccentricity [9]. In a series of papers, Allmaier et al. studied engine journal bearing lubrication by combining experimental measurements of friction and bearing temperature with hydrodynamic models [10-14]. Initial work employed VMfree oils but recently work on a formulated shear thinning oil has been reported [15]. This showed that it was essential to incorporate shear thinning effects to reliably predict friction performance. Unfortunately, the shear thinning measurements on which the study was based were obtained using a quartz crystal viscometer and it is questionable whether such measurements are comparable to viscosity measured in high shear systems.

This paper describes a study of the impact of lubricant shear thinning on bearing friction using a combined experimental and modelling approach. It is based on VM-containing lubricants whose shear thinning properties were fully characterised in [1]. After describing the experimental and modelling methods, results are presented in two sections. The first measures the friction of the bearing lubricated with a Newtonian oil and compares this with predicted friction in order to validate the approach. Interpretation is informed using a full thermo-hydrodynamic model. Then a series of VM-containing oils are studied in order to measure the impact of shear thinning on friction.

\section{Test Oils and Viscometrics}

In previous work, the authors investigated the temporary shear thinning properties of a base oil and a series of VM blends, all having the same HTHS viscosity of $3.7 \mathrm{mPa}$ s (at $10^{6} \mathrm{~s}^{-1}, 150^{\circ} \mathrm{C}$ ) [1]. In the current work, a subset of these oils is studied, as listed in Table 1. The original oil codes used in $[1,2]$ have been retained. Oils \#1, \#4, \#5, \#7, and \#10 are simple solutions of different VMs in the same 6 cSt KinVis Group II base oil. Oil \#11 has the same base oil but contains both a VM and a detergent-inhibitor package. Oil \#18 is a mixture of PAOs blended to have an HTHS of $3.7 \mathrm{mPa}$ s and thus serves as a Newtonian reference oil. 
Table 1 VM-containing oils (\#1-\#17) and the reference oil (\#18) studied

\begin{tabular}{lllllllll}
\hline Oil & VM type & VM wt\% & DI pack & DI pack wt\% & KV100C $(\mathrm{cSt})$ & VI & Base oil type & HTHS (mPa s) \\
\hline$\# 1$ & SIP1 & 11.5 & - & - & 16.19 & 162 & G-II & 3.73 \\
$\# 4$ & SIP2 & 25.0 & - & - & 19.91 & 183 & G-II & 3.70 \\
$\# 5$ & A-OCP & 11.5 & - & - & 13.60 & 153 & G-II & 3.69 \\
$\# 7$ & D-PMA & 9.0 & - & - & 12.54 & 191 & G-II & 3.70 \\
$\# 10$ & PMA & 13.5 & - & - & 11.40 & 276 & G-II & 3.77 \\
$\# 11$ & SIP3 & 15.7 & D1 & 11.9 & 13.73 & 178 & G-II & 3.73 \\
$\# 18$ & None & - & - & - & 12.48 & 148 & G-IV & 3.70 \\
\hline
\end{tabular}

$S I P$ hydrogenated styrene isoprene, $O C P$ olefin copolymer, $P M A$ polymethacrylate, $S B R$ hydrogenated styrene butadiene, $D$ dispersant, $A$ amorphous
Further information on these oils can be found in [1].

The dynamic viscosity of all the above oils was measured over a wide shear rate range up to $10^{7} \mathrm{~s}^{-1}$ as described in [1], and it was found that their viscosity versus shear rate behaviour at a given temperature could be described by the Carreau-Yasuda equation [16]:

$\eta=\eta_{\infty}+\left(\eta_{\mathrm{o}}-\eta_{\infty}\right)\left(1+(A \dot{\gamma})^{a}\right)^{\left(\frac{n-1}{a}\right)}$,

where $\eta$ is the dynamic viscosity of the fluid at shear rate $\dot{\gamma} ; \eta_{\mathrm{o}}$ is the first Newtonian viscosity; $\eta_{\infty}$ is the second Newtonian viscosity (approximated to the viscosity of the blend's base oil) and $A ; n$ and $a$ are constants of fit.

It was also found that for all except oil \#10, the shear thinning curves at different temperatures could be collapsed onto a single curve by using time temperature superposition in which the shear rate is multiplied by a shift factor $a_{\mathrm{T}}$, to give a reduced shear rate, $\dot{\gamma}_{\mathrm{r}}=a_{\mathrm{T}} \dot{\gamma}$. The shift factor $a_{\mathrm{T}}$ is a shift from a reference temperature, $T_{\mathrm{R}}$, ( $60{ }^{\circ} \mathrm{C}$ in this study) at which $a_{\mathrm{T}}$ is taken to be unity, and is defined by Eq. 2 [17].

$a_{\mathrm{T}}=\frac{\left[\eta_{\mathrm{o}}-\eta_{\infty}\right]_{(T)}}{\left[\eta_{\mathrm{o}}-\eta_{\infty}\right]_{\left(T_{\mathrm{R}}\right)}} \cdot \frac{T_{\mathrm{R}}}{T}$

This allows a single reduced Carreau-Yasuda equation to be developed to describe how viscosity varies with both shear rate and temperature for a given VM blend:

$\eta=\eta_{\infty}+\left(\eta_{\mathrm{o}}-\eta_{\infty}\right)\left(1+\left(A_{\mathrm{r}} a_{\mathrm{T}} \dot{\gamma}\right)^{a_{\mathrm{r}}}\right)^{\left(\frac{n_{\mathrm{r}}-1}{a_{\mathrm{r}}}\right)}$,

where the three constants $A_{\mathrm{r}}, n_{\mathrm{r}}$ and $a_{\mathrm{r}}$ are now best fits to the measured viscosity values of the blend at all shear rates and temperatures [1].

The above means that viscosity of a VM blend can be calculated at any shear rate and temperature of interest so long as (i) the reduced Carreau Yasuda contacts $A_{\mathrm{r}}, n_{\mathrm{r}}$ and $a_{\mathrm{r}}$ are known for the blend and (ii) the low shear rate
Table 2 Reduced CarreauYasuda constants for VM blends (reference temperature $T_{\mathrm{R}}=$ $\left.60{ }^{\circ} \mathrm{C}\right)$

\begin{tabular}{lrll}
\hline Test oil & $A_{\mathrm{r}}(\mu \mathrm{s})$ & $n_{\mathrm{r}}$ & $a_{\mathrm{r}}$ \\
\hline$\# 1$ & 21.88 & 0.36 & 1.00 \\
$\# 4$ & 68.39 & 0.47 & 1.00 \\
$\# 5$ & 18.41 & 0.66 & 1.52 \\
$\# 7$ & 21.13 & 0.75 & 2.26 \\
$\# 10$ & 1.70 & 0.69 & 1.60 \\
$\# 11$ & 39.36 & 0.75 & 2.50 \\
\hline
\end{tabular}

viscosities $\eta_{\mathrm{o}}$ and $\eta_{\infty}$ are known or can be calculated at the temperature of interest and at the reference temperature.

Table 2 lists the reduced Carreau Yasuda constants of the VM blends studied in this work. As discussed in [1], oil \#10 did not show satisfactory time temperature superposition collapse using the shift factor expression in Eq. 2. This was addressed by allowing $a_{\mathrm{T}}$ for this oil to vary with temperature empirically, based on experimental measurements at different temperatures. For oil \#10, viscosity can be thus predicted by using the Carreau-Yasuda constants in Table 2, but multiplying the value of $a_{\mathrm{T}}$ calculated from Eq. 2 by the factor $1,1.3,3.2,3.7,3.7$ at $60{ }^{\circ} \mathrm{C}, 80^{\circ} \mathrm{C}, 100{ }^{\circ} \mathrm{C}, 120{ }^{\circ} \mathrm{C}$ and $150{ }^{\circ} \mathrm{C}$, respectively, and allowing this factor to vary linearly with temperature between these bounding values at intermediate temperatures.

The required values of low shear rate viscosities $\eta_{\mathrm{o}}$ and $\eta_{\infty}$ at both the temperature of interest and the reference temperature of $60{ }^{\circ} \mathrm{C}$ can be straightforwardly calculated from the Vogel viscosity-temperature equation, Eq. 4, using the Vogel fit constants for each fluid and its base fluid as listed in Table 3 .

$\eta_{o}=a_{0} e^{b_{\mathrm{o}} /\left(T-c_{\mathrm{o}}\right)}$

To illustrate the data on which this study is based, Fig. 1a shows the individual viscosity measurements for oil \#5 plotted against the reduced shear rate at four temperatures, together with the line fit by Eq. 3. The ordinate of this graph is the normalised viscosity or shear stability index (SSI) defined as 
Table 3 Low shear rate Vogel constants of VM blends and component base oils

\begin{tabular}{|c|c|c|c|c|c|c|}
\hline \multirow[t]{2}{*}{ Test oil } & \multicolumn{3}{|c|}{ Vogel constants of test oil (to determine $\eta_{\mathrm{o}}$ ) } & \multicolumn{3}{|c|}{$\begin{array}{l}\text { Vogel constants of corresponding base oil (to } \\
\text { determine } \eta_{\infty} \text { ) }\end{array}$} \\
\hline & Vogel $a_{\mathrm{o}}(\mathrm{mPa} \mathrm{s})$ & Vogel $b_{\mathrm{o}}\left({ }^{\circ} \mathrm{C}\right)$ & Vogel $c_{\mathrm{o}}\left({ }^{\circ} \mathrm{C}\right)$ & Vogel $a_{\mathrm{o}}(\mathrm{mPa} \mathrm{s})$ & Vogel $b_{\mathrm{o}}\left({ }^{\circ} \mathrm{C}\right)$ & Vogel $c_{\mathrm{o}}\left({ }^{\circ} \mathrm{C}\right)$ \\
\hline$\# 1$ & 0.11158 & 989.308 & -107.84 & 0.06322 & 883.001 & -103.24 \\
\hline \#4 & 0.12945 & 1028.18 & -113.64 & 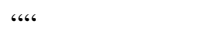 & “، & “، \\
\hline$\# 5$ & 0.0844 & 1024.21 & -110.63 & ““” & 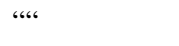 & ““” \\
\hline \#7 & 0.161106 & 850.124 & -105.28 & ““ & ““况 & 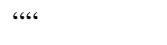 \\
\hline$\# 10$ & 1.13028 & 310.73 & -50.628 & « & «، & ،“، \\
\hline$\# 11$ & 0.19964 & 770.535 & -92.505 & “، & «، & ،“، \\
\hline$\# 18$ & 0.04839 & 1193.38 & -124.72 & - & - & - \\
\hline
\end{tabular}
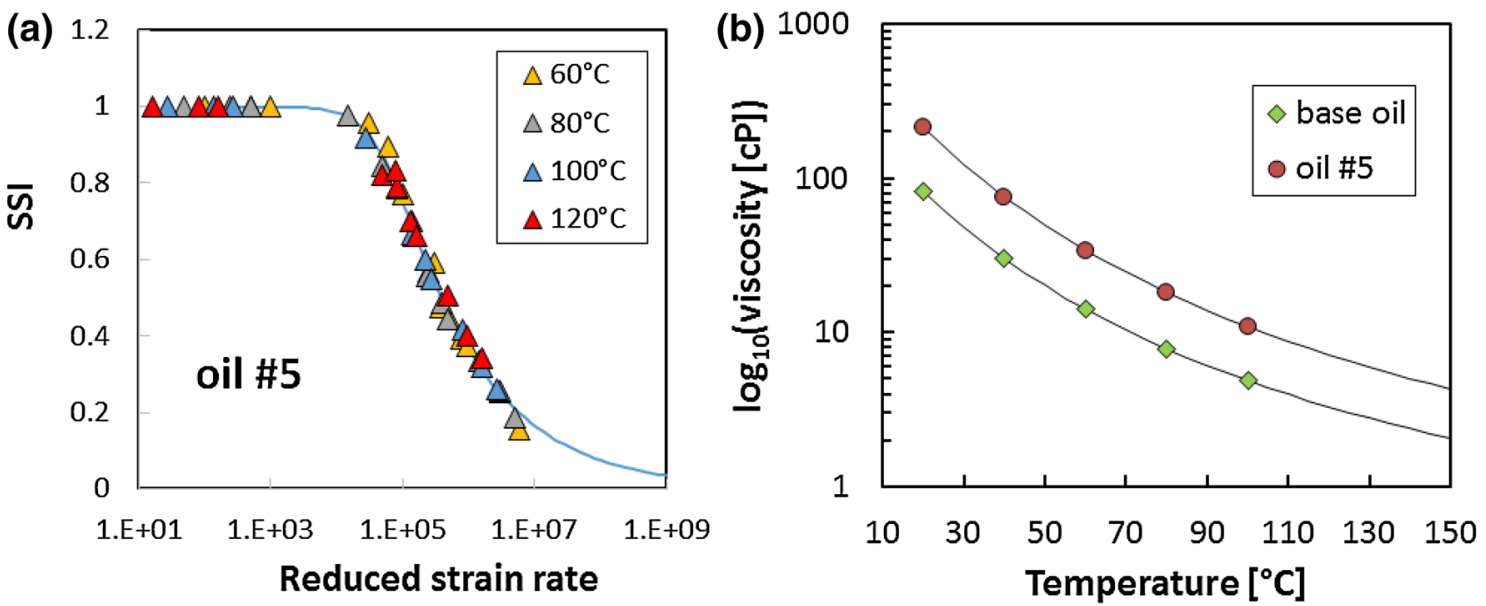

Fig. 1 a Measured SSI versus reduced strain rate and Carreau-Yasuda best fit for oil \#5. b Measured low shear rate viscosity versus temperature and Vogel equation best fits for oil \#5 and base oil used in the VM blends

$\operatorname{SSI}=\frac{\left(\eta-\eta_{\infty}\right)}{\left(\eta_{0}-\eta_{\infty}\right)}$.

Figure $1 \mathrm{~b}$ shows low shear rate measurements and Vogel best fits for oil \#5 and also the base oil used in the VM blends.

\section{Method: Journal Bearing Machine (JBM)}

Friction tests were carried out using a Journal Bearing Machine (JBM), PCS Instruments, Acton, UK. The rig consists of a lined steel shaft that rotates inside a commercial engine bearing shell, made up of two half-shells housed in a modified connecting rod. It is shown in Fig. 2.

Load is applied to the bearing via a lever arm and can either be a steady load or a transient one in which an additional load is applied on top of a continuous one using a rotating cam, as shown in Fig. 3. In the current study, steady

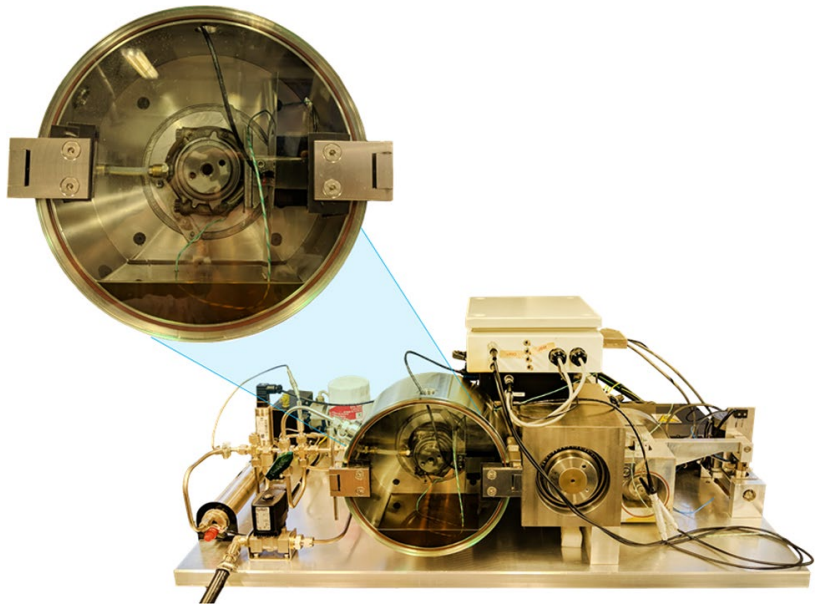

Fig. 2 Photograph of JBM

load conditions were used. The load is transferred via a coupling from which both the load and friction can be measured with strain gauge load cells. In practice, this set-up provides 
Fig. 3 Schematic of loading system

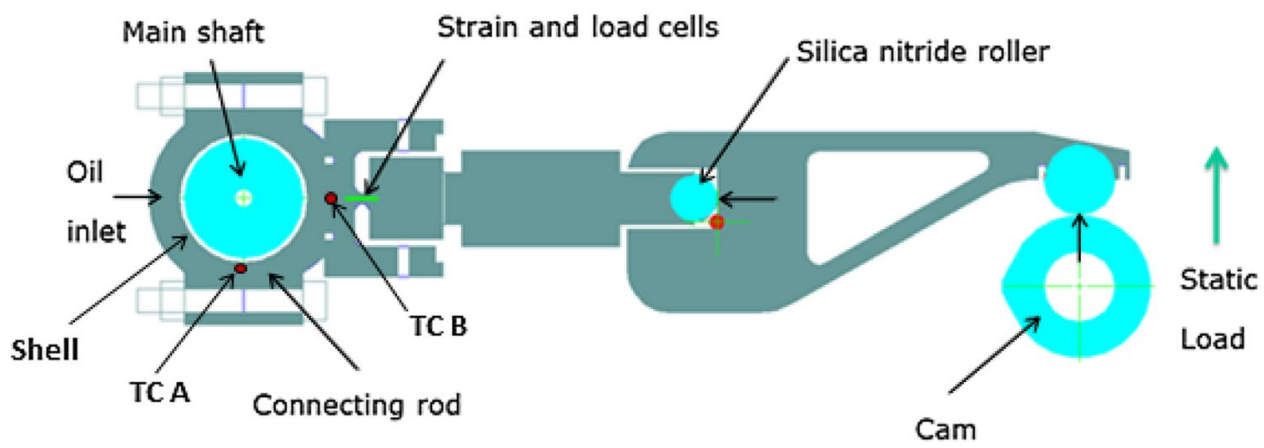

almost but not quite perfect isolation of the normal applied force (load) from the lateral force (torque and thus friction), so that a small proportion of the load appears in the friction measurement. Because the friction coefficient is only ca $0.001-0.01$, this load contribution is significant. In order to eliminate it, two measurements are averaged with the shaft rotating in opposite directions, which has the effect of cancelling the load contribution from the friction measurement.

In the current study, commercial Chrysler plain bearings (3.6 L, V6 engine) were used, of length $L=17.8 \mathrm{~mm}$ with shaft diameter, $D=59.5 \mathrm{~mm}$. The radial clearance was 29 $\mu \mathrm{m}$. Tests were carried out at eight rotational speeds ranging from 1000 to $3500 \mathrm{rpm}$, three loads in the range $1-3 \mathrm{kN}$ (corresponding to bearing pressures of 1-3 MPa) and oil supply temperatures of $60,80,100$ and $120^{\circ} \mathrm{C}$. Oil was supplied at $150 \mathrm{kPa}$ pressure. A new pair of bearing half-shells from a single batch was used for each test oil. This was run in with the test oil over a series of decreasing loads, $10 \mathrm{kN}$, $7 \mathrm{kN}, 5 \mathrm{kN}, 3 \mathrm{kN}$. At each run-in load stage, the shaft was rotated in both directions at each of the eight test speeds.

Although oil is supplied at a controlled temperature, it is important when analysing plain journal bearing performance to appreciate that the actual oil film temperature can be quite different from the oil supply temperature. At $3000 \mathrm{rpm}$ and 3 $\mathrm{kN}$ load, the power loss in the bearing was typically $100 \mathrm{~W}$ in this study and this resulted in a rapid rise in bearing temperature. The final, steady-state oil film temperature depends on the heat transfer properties of the bearing and its holder as well as on the oil supply temperature.

In order to monitor temperature and explore the thermal properties of the bearing, thermocouples were used in the JBM as illustrated in Fig. 3. Thermocouple A (TC A) is mounted between the bearing shell and the connecting rod housing at $90^{\circ}$ from the applied load position. When the shaft rotates in a clockwise direction, the minimum film thickness moves round the bearing so that thermocouple A is in the cavitating zone at a bearing angle of $270^{\circ}-\psi$, where $\psi$ is the attitude angle, as shown in Fig. 19a in the Appendix. Thermocouple B (TC B) is located between piston rod and the loading system. A third thermocouple is placed in the test chamber close to the connecting rod to monitor the ambient temperature experienced by the latter's outer surface. The fourth thermocouple measures the oil supply temperature and uses this via a feedback loop to stabilise this at a set value.

The experimental test protocol was as follows:

(i) The test rig was cleaned and flushed eight times with $300 \mathrm{ml}$ of test oil before being filled with $500 \mathrm{ml}$ of test oil.

(ii) Oil supply temperatures of $120^{\circ} \mathrm{C}, 100^{\circ} \mathrm{C}, 80{ }^{\circ} \mathrm{C}$, $60{ }^{\circ} \mathrm{C}$ were studied in succession.

(iii) For each oil supply temperature, the oil was circulated while running the bearing at $3000 \mathrm{rpm}$ and 3 $\mathrm{kN}$ load until both the set oil supply temperature and the bearing temperature (measured by thermocouple A) stabilised. This generally took about 10-20 min.

(iv) Friction was then measured at a series of applied loads and speeds.

It should be noted that because two friction measurements were made, with the shaft rotating in opposite directions, thermocouple A switched positions from being in the cavitation region (at about $230^{\circ}$ ) to the active converging zone (at about $50^{\circ}$ ) as the shaft changed direction. This provided two measurements of temperature around the bearing. In this paper, only the measurement made in the cavitation region is utilised.

\section{Shear Thinning Thermohydrodynamic Bearing Model}

A finite difference-based 3D thermal model was used to analyse the hydrodynamic and heat transfer behaviour of the lubricated bearing. This is based on iterative solution of (i) a 3D generalised Reynolds equation to determine flow and pressure in the oil film, (ii) the reduced Carreau Yasuda equation to determine viscosity at local shear rate and temperature, (iii) the energy equation to determine the temperature distribution in the oil film and (iv) the Laplace equation to determine the heat flux through the bearing shell 
and connecting rod holder. Further details of this model are provided in "Appendix".

It is important to note that this model was not intended to simulate precisely the bearing under study, which would have required inclusion of the complex geometry of the connecting rod, as well as accurate thermal properties of all of the materials and measurement of the heat transfer properties of the relevant surfaces. Such simulation is feasible but was not within the scope of the study. Instead the model was based on an idealised cylindrical bearing geometry with representative heat transfer constants and was intended primarily to inform on the general distribution of temperature in the bearing system and, as outlined in Sect. 6 below, to justify the use of an isothermal model based on an effective oil film temperature. However, it also provided a way to compare directly the impact of different VMs in a thermohydrodynamic bearing.

\section{JBM Study Using Newtonian Oils}

Initial work was carried out with the Newtonian base oil \#18 to develop a test methodology for taking account of bearing temperature. Figure 4 shows how friction varied with shaft speed at three loads and a fixed oil supply temperature. As expected, friction increases with speed and load. Tests also showed that friction reduced with increasing oil supply temperature at a given load and speed and was relatively insensitive to variations of load at fixed speed and oil supply temperature.

Figure 5 shows all the friction measurements made (at 3 loads and 8 speeds at $80{ }^{\circ} \mathrm{C}, 100^{\circ} \mathrm{C}$ and $120^{\circ} \mathrm{C}$ and one load and 8 speeds at $60{ }^{\circ} \mathrm{C}$ ) in classical Stribeck form of friction coefficient versus $u_{\mathrm{s}} \eta_{\text {supply }} / W$, where $u_{\mathrm{s}}$ is the shaft surface speed, $W$ is the applied load and $\eta_{\text {supply }}$ is the viscosity at the

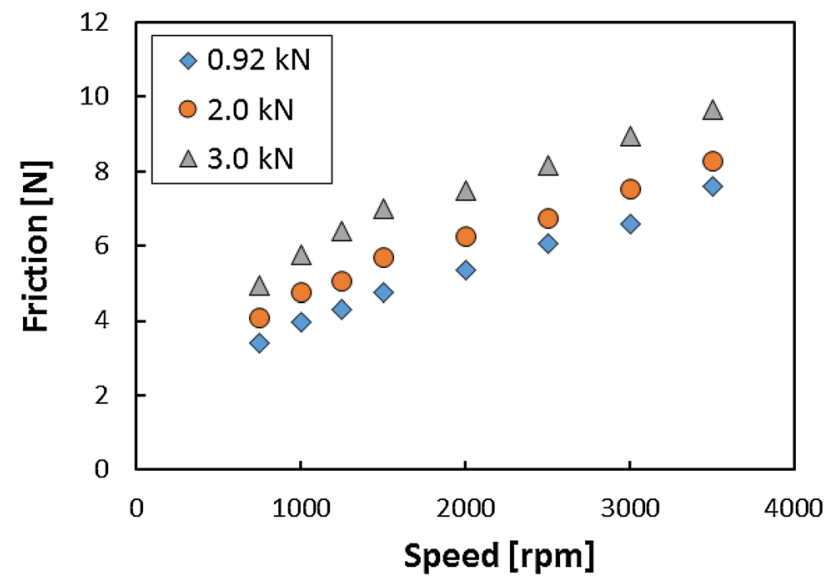

Fig. 4 Influence of sliding speed on friction for oil \#18 at 3 loads and $120^{\circ} \mathrm{C}$

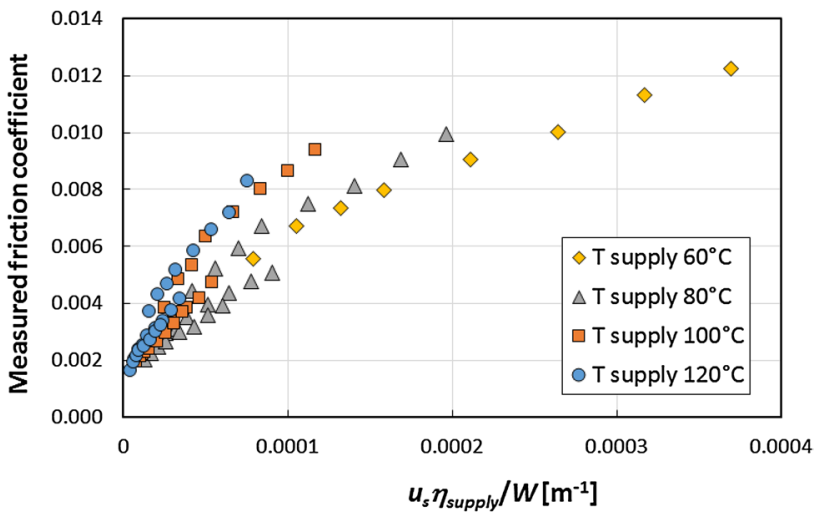

Fig. 5 Friction coefficient versus $u_{\mathrm{s}} \eta_{\text {supply }} / W$ for oil $\# 18$ at all loads and speeds

oil supply temperature. The measurements fall on separate curves, with friction coefficient values obtained at higher oil supply temperatures being greater than those measured at lower temperatures.

Figure 6 shows the same friction coefficient data plotted against the Stribeck number $u_{\mathrm{s}} \eta_{\text {eff }} / W$ where $\eta_{\text {eff }}$ is now the viscosity of the oil at the temperature measured by thermocouple A, between the bearing shell and its holder in the cavitation zone. This has the effect of collapsing the data onto a single curve, as expected from isothermal journal bearing theory. It confirms the importance of taking account of thermal effects when interpreting and predicting friction in journal bearing lubrication.

The thermo-hydrodynamic model was used to determine the temperature distribution in the lubricated bearing. This is illustrated in Figs. 7 and 8 for a bearing operating with oil \#18 at $3000 \mathrm{rpm}, 2 \mathrm{kN}$ and $80{ }^{\circ} \mathrm{C}$ oil supply temperature. Figure 7 shows how the predicted mid-oil film temperature varies round the bearing. The oil film heats up in the converging region and then stabilises over most of the high

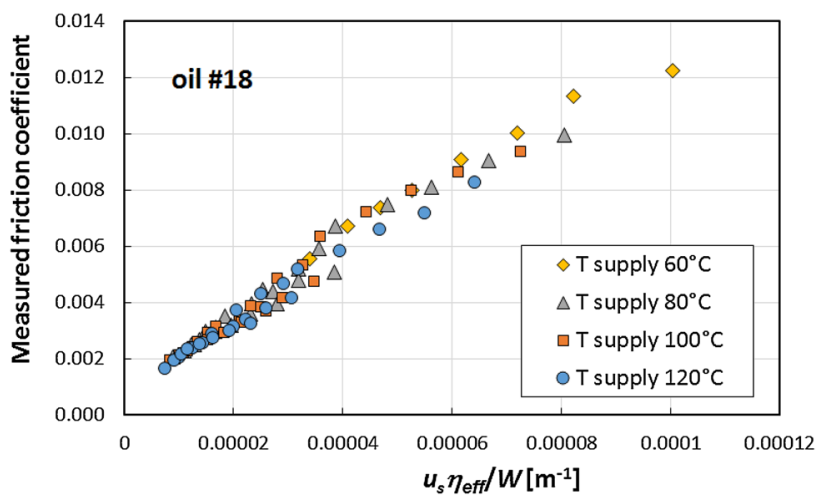

Fig. 6 Friction coefficient versus $u_{\mathrm{s}} \eta_{\mathrm{eff}} / W$ for oil \#18 at all loads and speeds; $\eta_{\text {eff }}$ is the viscosity at temperature measured by thermocouple A during each test 


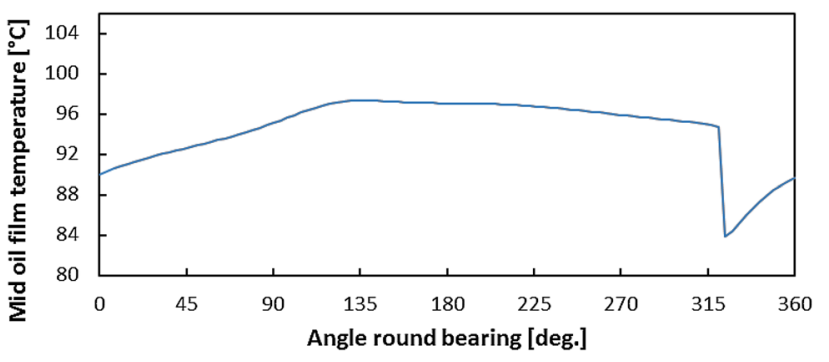

Fig. 7 Predicted variation of mid-oil film temperature around bearing lubricated by base oil \#18 at $3000 \mathrm{rpm}, 2 \mathrm{kN}$ load and oil supply temperature $80{ }^{\circ} \mathrm{C}$

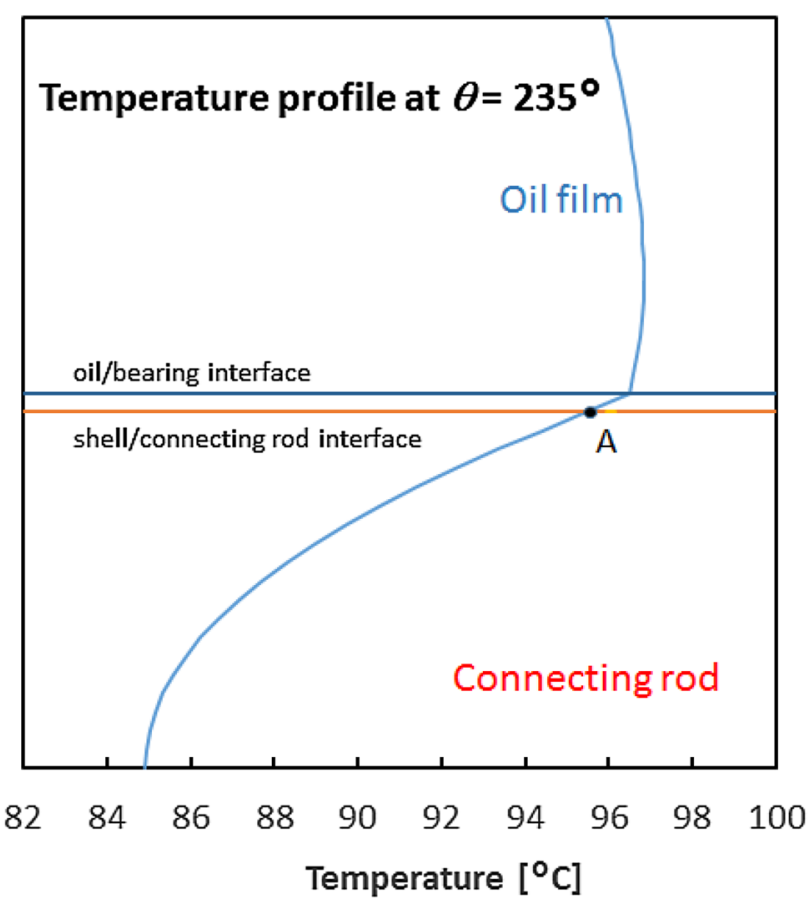

Fig. 8 Predicted variation of temperature through the oil film and the sleeve/connecting rod at bearing angle $235^{\circ}$ and $y=0$. Bearing lubricated by base oil \#18 and operating at $3000 \mathrm{rpm}, 2 \mathrm{kN}$ load and oil supply temperature $80{ }^{\circ} \mathrm{C}$, ambient temperature $70{ }^{\circ} \mathrm{C}$. Location of thermocouple A shown

pressure and cavitation zone at a value of between 95 and $96{ }^{\circ} \mathrm{C}$. It then falls sharply as fresh oil at $80{ }^{\circ} \mathrm{C}$ is supplied to fill the gap. Since the eccentricity ratio is $c a$. 0.75 , only about $15 \%$ of the originally supplied oil passes through the minimum film thickness, so $85 \%$ is supplied as fresh oil at $80{ }^{\circ} \mathrm{C}$. Of note is the fact that the bearing temperature is quite constant over most of the load supporting region. This is primarily because the shaft temperature is constant in the circumferential direction, which imposes a stabilising boundary condition on the oil film.

Figure 8 shows how the predicted temperature varies through the oil film at one location of the bearing (mid line in the axial direction, and $235^{\circ}$ around the bearing and thus in the cavitation zone very close to thermocouple A). The temperature profiles through both an oil film streamer and the bearing/connecting rod are shown (the depth scales are of course quite different for the two). This plot shows that the thermocouple A located just below the shell will measure a temperature slightly lower that the oil/bearing interface temperature and that the temperature variation across the bearing is small, as expected since the oil film is thin.

Because most of the thin film region of the bearing, where the bulk of the friction originates, is at quite constant temperature, it is possible to use an isothermal solution to determine bearing friction, based on a single "effective temperature" and thus an effective oil viscosity. Such an isothermal, effective viscosity approach has been quite widely applied in bearing design [18, 19] and Allmaier suggested a weighted average temperature from four thermocouples distributed around a bearing to determine the effective bearing temperature [13]. To test the validity of the isothermal approximation for the current study, the thermohydrodynamic model was used to determine the bearing temperature distribution and friction over a wide range of conditions (1000-3500 rpm, 1 to $4 \mathrm{kN}$ and 60 to $120^{\circ} \mathrm{C}$ supply temperature) for both the reference oil \#18 and a shear thinning oil \#1. The predicted friction was then compared with the friction calculated using an isothermal model based on individual temperatures determined at various locations in the bearing from the full thermo-hydrodynamic model. It was found that the bearing temperature at the location of thermocouple A (i.e. $1.4 \mathrm{~mm}$ below the oil/sleeve interface at a bearing angle of $270^{\circ}-\psi$ ) employed in an isothermal solution gave a friction prediction within $0.5 \%$ of that from

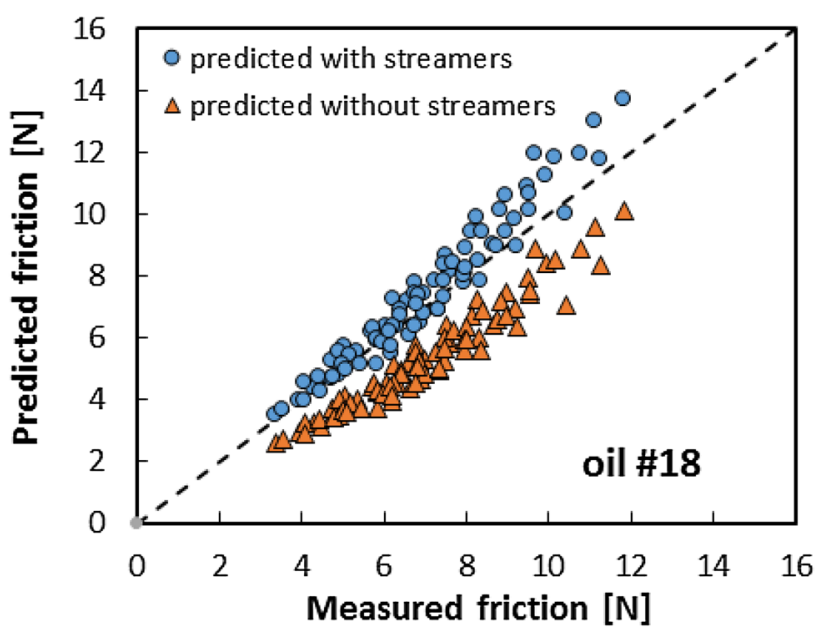

Fig. 9 Plot of predicted versus measured friction for all measured data. Predicted friction is calculated assuming the bearing is isothermal at the temperature measured by thermocouple $\mathrm{A}$ 
the full thermo-hydrodynamic solution for all conditions and oils tested.

Figure 9 shows the predicted bearing friction from the isothermal hydrodynamic model using the temperatures measured with thermocouple A plotted against the measured friction for all the measured friction values for Oil \#18. Two sets of predicted friction values are shown, one assuming a full set of cavitation streamers as discussed in the Appendix and the other assuming absence of cavitation streamers. There is good agreement between measured friction and friction predicted assuming the presence of cavitation streamers. These both validate the JBM measurements and also provide supportive evidence for the occurrence (and importance to friction) of cavitation streamers. At high friction, which corresponds to high-speed conditions, the measured friction falls slightly below the predicted friction. This is probably due to the inlet meniscus moving slightly upstream and/or some break-up of the cavitation streamers.

The above work using a Newtonian reference oil shows that bearing friction can be measured accurately using the JBM and also predicted using an isothermal approach based on an effective oil film temperature. Similar measurements and analysis were made on the relatively low viscosity base oil used in the VM-containing oils \#1-\#11 and showed equally good agreement between measurement and prediction. This indicates that there is negligible contribution from boundary friction, which is perhaps unsurprising since the predicted minimum film thickness formed by this base oil (at $750 \mathrm{rpm}, 3 \mathrm{kN}$ load and $120^{\circ} \mathrm{C}$ ) was $1.2 \mu \mathrm{m}$, while the bearing roughness was less than $600 \mathrm{~nm} \mathrm{Rq}$.

\section{JBM Study Using VM-Containing Oils}

Friction and bearing temperature were measured for the VM-containing oils over the same range of conditions as the reference oil. However, direct quantification of the impact of VMs on journal bearing friction is not straightforward since friction and temperature are coupled and both vary from test to test. Nor was it possible to ensure that the bearing always reached full thermal equilibrium. Friction values measured at the same speed and load for different oils are thus not directly comparable.

One approach is to use the measured temperature at thermocouple A as an effective oil film temperature, as outlined in the previous section, and use this to determine the effective low shear rate viscosity of the test oil at that temperature. Friction coefficient can then be plotted against $u_{\mathrm{s}} \eta_{\mathrm{eff}} / W$ where $\eta_{\text {eff }}$ is the effective viscosity at the mean bearing temperature. This is shown for oils \#1 and \#4 in Fig. 10a, b. The best fit line to data of friction versus $u_{\mathrm{s}} \eta_{\mathrm{eff}} / W$ for reference oil \#18 (from Fig. 6) is shown as a dashed line. It is clear that the VM-containing oils give considerably lower friction than
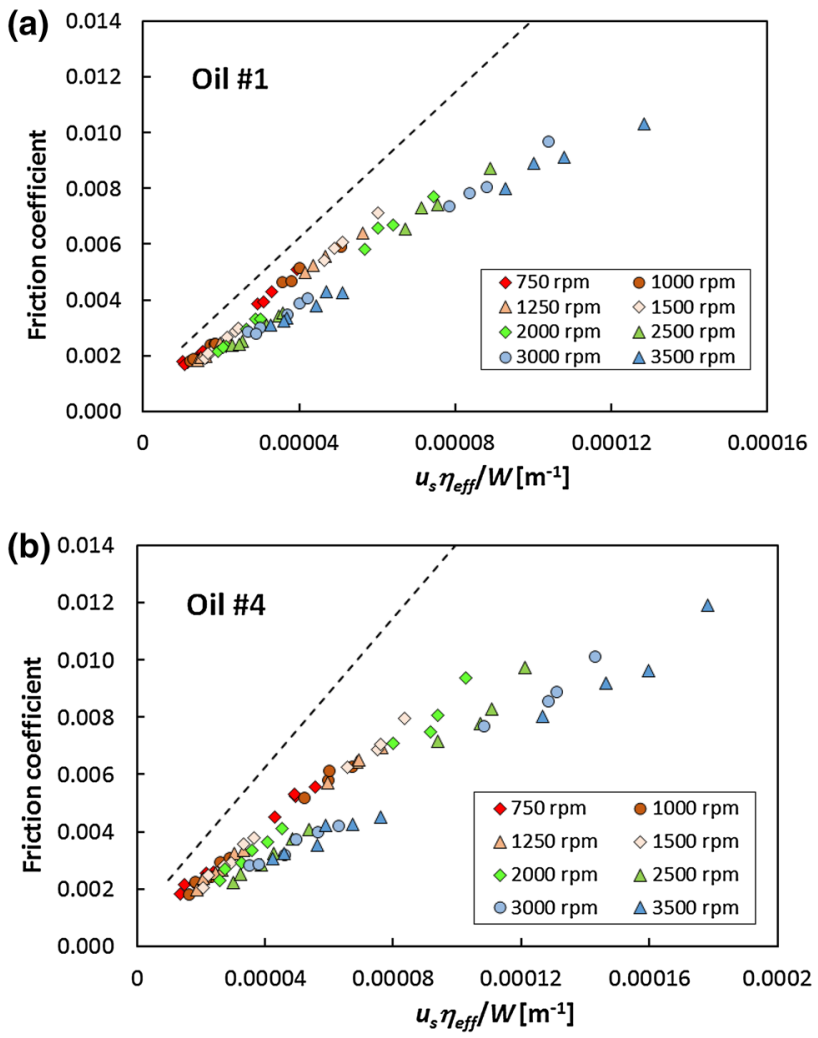

Fig. 10 Plots of measured friction coefficient versus the Stribeck number $u_{\mathrm{s}} \eta_{\text {eff }} / W$ where $\eta_{\text {eff }}$ is the low shear rate viscosity of the oil at the effective bearing temperature for all tests on a oil \#1 and $\mathbf{b}$ oil \#4

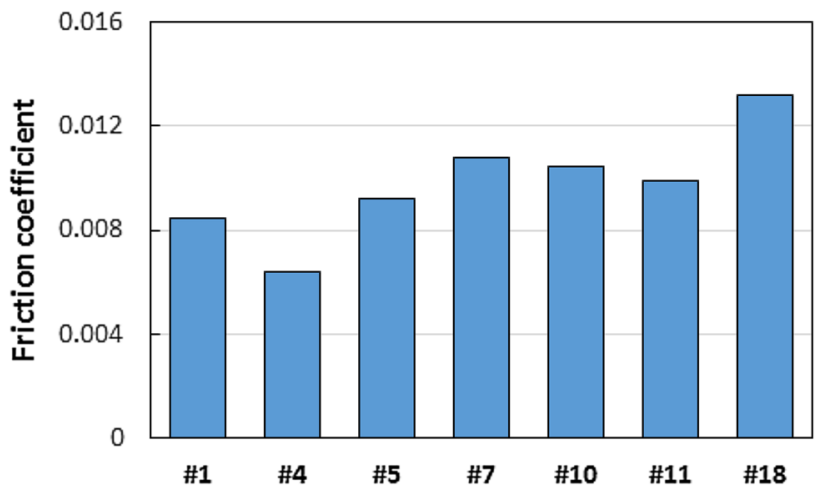

Fig. 11 Friction coefficient at $u_{\mathrm{s}} \eta_{\mathrm{eff}} / W=0.0001 \mathrm{~m}^{-1}$ based on measured data at a bearing speed of $3000 \mathrm{rpm}$

the VM-free oil in these Stribeck-type plots. However, unlike the reference oil, the data do not collapse on to a single line but vary systematically with bearing speed. This is because the oils' effective viscosities reduce with increasing shear rate and thus sliding speed.

Figure 11 compares the bearing friction of all the test oils at $u_{\mathrm{s}} \eta_{\mathrm{eff}} / W=0.0001$ at $3000 \mathrm{rpm}$ based on best fits through all of the measured data at this bearing speed. This shows 


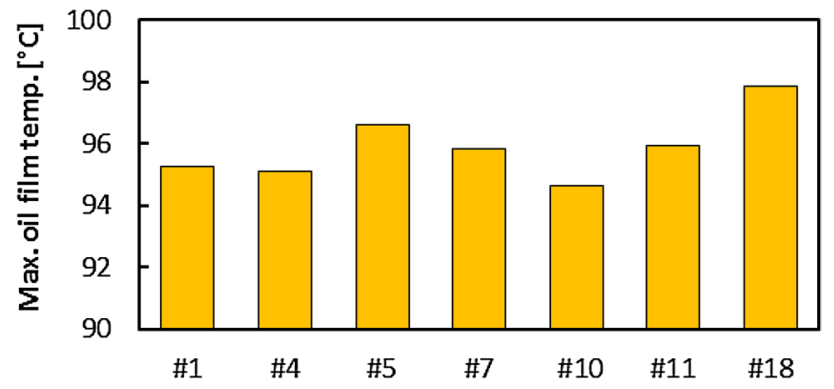

Fig. 12 Maximum oil film temperature at $3000 \mathrm{rpm}, 2 \mathrm{kN}$ load, $80^{\circ} \mathrm{C}$ oil supply temperature; from thermo-hydrodynamic model

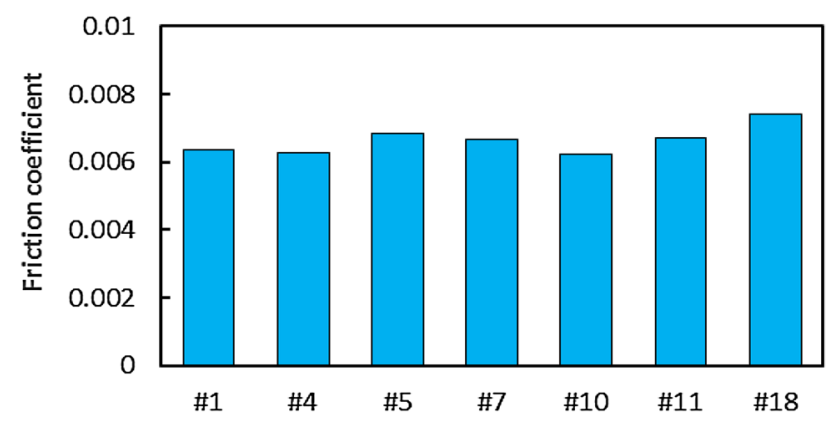

Fig. 13 Calculated friction coefficient at $3000 \mathrm{rpm}, 2 \mathrm{kN}$ load, $80{ }^{\circ} \mathrm{C}$ oil supply temperature; from thermo-hydrodynamic model

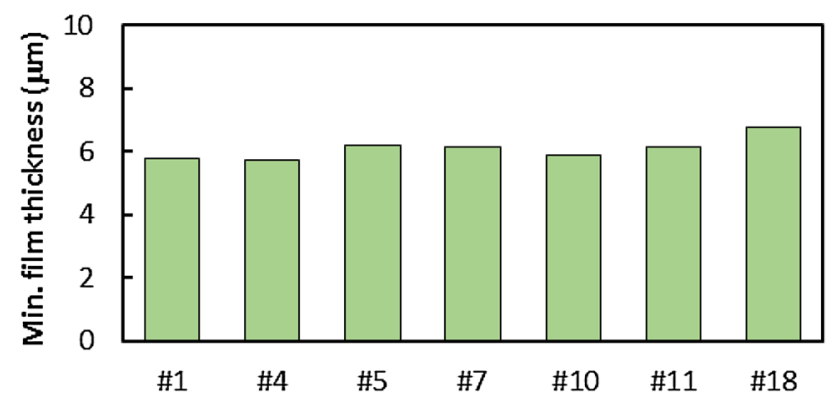

Fig. 14 Calculated minimum film thickness at $3000 \mathrm{rpm}, 2 \mathrm{kN}$ load, $80{ }^{\circ} \mathrm{C}$ oil supply temperature; from thermo-hydrodynamic model

clearly that all six of the VM-containing oils in a $6 \mathrm{cSt}$ base oil show considerably lower friction than the reference oil.

More detailed comparison of the various VM blends could only be made using the full thermo-hydrodynamic model to compare bearing temperature and friction for different blends at the same load, speed and oil supply temperature.

Figures 12, 13, 14 show the predicted maximum temperature reached in the oil film, the friction coefficient and the minimum film thickness respectively for all the oils at $3000 \mathrm{rpm}, 2 \mathrm{kN}$ load and an oil supply temperature of $80{ }^{\circ} \mathrm{C}$.

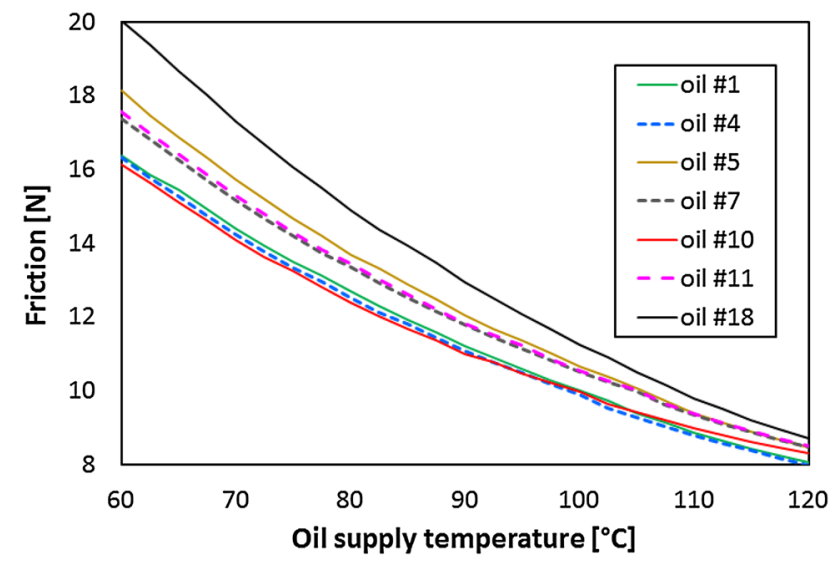

Fig. 15 Variation of calculated friction with oil supply temperature at $3000 \mathrm{rpm}, 2 \mathrm{kN}$ load; from thermo-hydrodynamic model

It is evident that all the VM-containing oils show both lower friction and consequently lower oil film temperature than the Newtonian reference oil, despite the latter having a smaller low shear rate viscosity. The VM-containing oils operate typically 2 to $4{ }^{\circ} \mathrm{C}$ lower than the reference oil and show between 10 and $15 \%$ lower friction. Film thicknesses of the VM-containing oils are also about 10-15\% lower than the reference oil. Oils \#1, \#4 and \#10 show the lowest friction.

Figure 15 shows how predicted bearing friction varies with oil supply temperature for all of the test oils at $3000 \mathrm{rpm}$ and $2 \mathrm{kN}$ load. Friction drops rapidly with oil supply temperature (and thus bearing temperature) for all oils, with oils \#1, \#4 and \#10 showing the lowest friction in accord with Fig. 13. It should be noted that the friction values are not produced by oil films at the supply temperature shown, but at the considerably higher temperatures reached within the bearing. These are typically $80{ }^{\circ} \mathrm{C}, 95^{\circ} \mathrm{C}, 110^{\circ} \mathrm{C}$ and $130{ }^{\circ} \mathrm{C}$ at $60{ }^{\circ} \mathrm{C}, 80{ }^{\circ} \mathrm{C}, 100^{\circ} \mathrm{C}$ and $120^{\circ} \mathrm{C}$ oil supply temperature, respectively.

\section{Discussion}

The aim of this study was to explore the impact of viscosity modifier additives on friction in an engine bearing. However, bearing temperature rise plays a key role in controlling friction which means that, while tests can be carried out at a fixed oil supply temperature, it is not possible to conduct them at a controlled oil film temperature since oil film temperature and friction are coupled. Three essential components of the current work were therefore (i) the availability of a single equation for each VM blend (Eq. 3) that describes the dependence of viscosity on both shear rate and temperature; (ii) a bearing rig in which both friction 
and temperature can be measured; and (iii) a hydrodynamic model incorporating thermal and shear thinning behaviour.

In practice, it was not practicable to measure temperature of the actual oil film within the bearing, but the thermohydrodynamic model shows that bearing friction can be predicted reliably based on an isothermal hydrodynamic model using a single temperature measurement from between the bearing shell and its holder in the cavitation zone. Based on this measured temperature, close fit between measured and predicted friction was obtained, as shown in Fig. 9. Interestingly, the friction values measured appear to support the presence within the bearing of a full set of cavitation streamers under most conditions. Figure 16 shows similar graphs of friction predicted from the isothermal model based on thermocouple A plotted against measured friction for the VMcontaining oils \#1 and \#10. These show close agreement at low bearing speeds but, as also seen with oil \#18, lower than predicted friction at high speeds. Again this may be due to movement of the inlet meniscus and/or some breakdown of cavitation streamers.

Figure 13 compares the predicted friction coefficients of the test oils at a fixed load, speed and supply temperature, and shows that the VM-containing oils give lower friction that the reference oil. It is important to recognise that this reduction in friction reflects, quite simply, a lower effective viscosity at the prevailing temperature and shear rate conditions in the oil film and that there are two factors that contribute to this low viscosity; (i) low shear rate viscosity and (ii) shear thinning. These two factors explain the considerable difference in friction reduction of the test oils shown between Figs. 11 and 13. Figure 13 shows friction predicted from the thermo-hydrodynamic model, where both variations of low shear rate viscosity and shear thinning within the bearing are taken into account when calculating friction. However in Fig. 11, which incorporates the low shear rate viscosity of the oil at the bearing temperature, $\eta_{\mathrm{eff}}$, in the Stribeck number, only the residual effect of shear thinning is shown.

Using the thermo-hydrodynamic model, it is straightforward to explore the impact of shear thinning on friction by comparing solutions in which shear thinning takes place with those when the same oil is not allowed to shear thin. This impact is defined as

Friction reduction due to shear thinning \%

$$
=\frac{F_{\text {Newtonian }}-F_{\text {shear thinning }}}{F_{\text {Newtonian }}} \times 100 \text {. }
$$

Figure 17 shows the percentage friction reduction for the VM blends resulting from shear thinning, as predicted from the thermo-hydrodynamic model.

This matches Fig. 11 quite closely and shows that oils \#1 and \#4 provide a large friction reduction due to shear thinning while oil \#10 shows minimal such friction reduction.

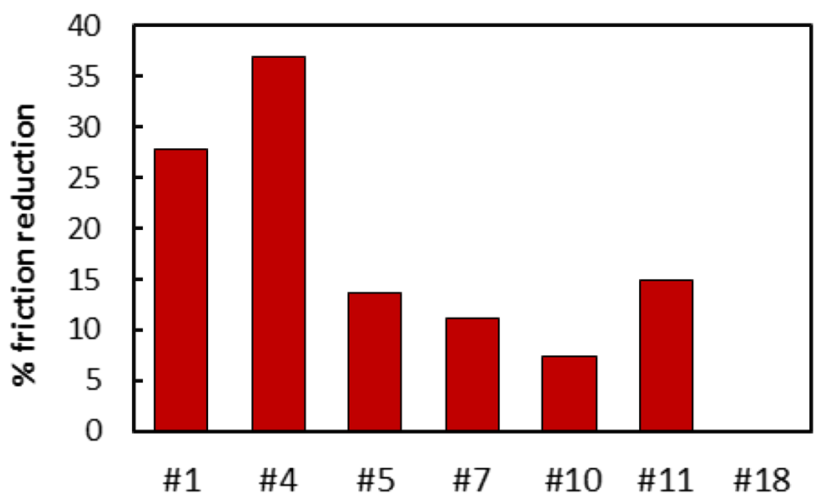

Fig. 17 Percentage friction reduction due to shear thinning at $3000 \mathrm{rpm}, 2 \mathrm{kN}$ load, $80{ }^{\circ} \mathrm{C}$ oil supply temperature; from thermohydrodynamic model
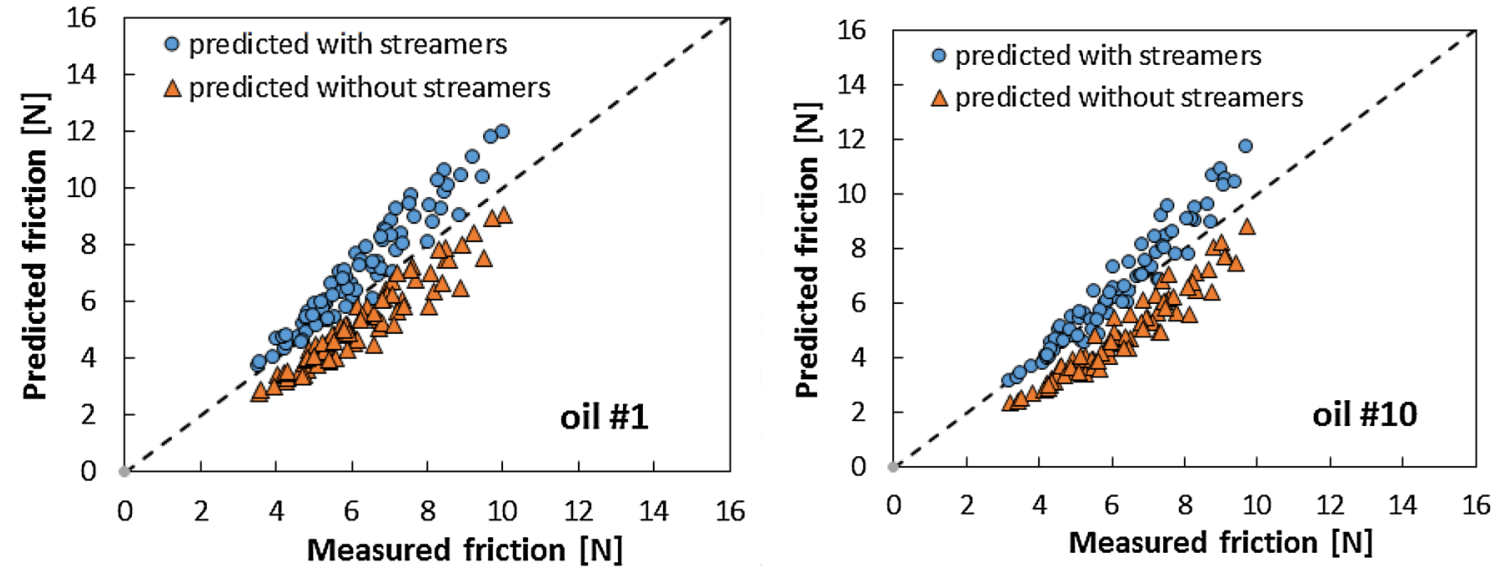

Fig. 16 Plot of predicted versus measured friction for all measured data for two VM-containing oils. Predicted friction is calculated assuming the bearing is isothermal at the temperature measured by thermocouple $\mathrm{A}$ 


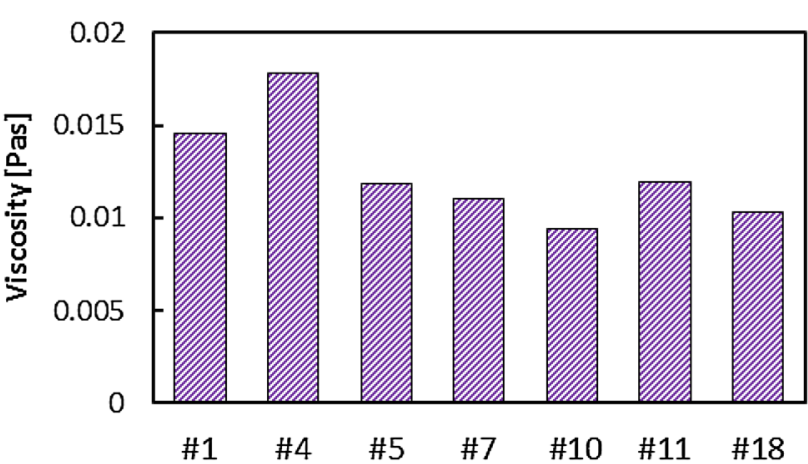

Fig. 18 Low shear rate viscosities of the test oils at their maximum oil film temperatures (shown in Fig. 12) at $3000 \mathrm{rpm}, 2 \mathrm{kN}$ load, $80{ }^{\circ} \mathrm{C}$ oil supply temperature; from thermo-hydrodynamic model

Oil \#10 shows very little shear thinning because, as discussed in [1], it has relatively little thickening power below $100^{\circ} \mathrm{C}$ and also it only shear thins significantly at very high shear rates.

Figure 18 compares the low shear rate viscosities of the test oils at the maximum prevailing oil film temperatures shown in Fig. 12. As might be expected these values parallel quite closely the KV100 values listed in Table 1. Oils \#1 and \#4 have relatively high low shear rate viscosities and these negate to some extent the contribution of shear thinning to their friction reduction. Oil \#10, because of its extremely high VI, has relatively low viscosity at the bearing temperature, which more than compensates for its minimal shear thinning.

The actual bearing friction shown in Fig. 13 results from a combination of the two factors shown in Figs. 17 and 18, shear thinning and low shear rate viscosity and, since these appear to be inversely correlated, mean that all of the VM oils produced quite similar friction values. Another factor driving this similarity is thermal feedback, where oils that give low friction produce less shear heating, so their bearings run slightly cooler, which results in a higher viscosity and thus higher friction. This feedback process reduces the differences in friction between the oils in a thermo-hydrodynamic bearing but in practice has a relatively minor effect compared to the factors illustrated in Figs. 17 and 18.

It is of interest to consider why the magnitude of shear thinning and low shear rate viscosity are inversely correlated for the VM-containing oils studied. This is simply because all the test oils were formulated to have the same value of $3.7 \mathrm{mPa}$ s HTHS. To achieve this value at $10^{6} \mathrm{~s}^{-1}$ and $150^{\circ} \mathrm{C}$, those oils that shear thin strongly require higher values of low shear rate viscosity than those that shear thin relatively little.

Although this constraint imposes limits to how widely the friction properties of the VM-containing oils studied here can vary, the differences shown in Fig. 13 are still significant, with oils \#1 and \#10 giving 8-9\% lower friction than oils \#5 and \#11. Without this constraint of requiring the same HTHS, it should be evident that for an oil to give low friction in an engine bearing it should combine low viscosity at low shear rate, a very high VI (so as to maintain low viscosity down to low temperatures) and a large amount of shear thinning at high bearing speeds.

\section{Conclusions}

This study has demonstrated the effectiveness of the JBM for studying the hydrodynamic friction properties of engine lubricants. It has also highlighted the importance of measuring or calculating actual bearing temperature in order to interpret friction results, since these temperatures are often quite different from oil supply temperatures.

Engine friction increases rapidly with increasing shaft speed but relatively slowly with increasing load.

It has been found, both experimentally and by comparison with the predictions of a thermo-hydrodynamic bearing model that an isothermal model incorporating shear thinning at an effective bearing temperature can be used to reliably predict bearing friction. The effective temperature is very close to the value measured using a thermocouple between sleeve and holder at a bearing angle of $270^{\circ}$ in the stationary, loaded bearing; $\left(270^{\circ}-\psi\right.$ when the shaft rotates).

The coupling of friction and temperature makes it difficult to compare quantitatively the impact of VMs on friction in the JBM since tests cannot be easily performed at the same effective bearing temperature. However, a thermohydrodynamic model incorporating shear thinning can be used to explore different VM blends. This is only possible because of (i) the availability of reliable measurements of viscosity up to $10^{7} \mathrm{~s}^{-1}$ and (ii) the recent development of equations that describe the dependence of lubricant viscosity on both shear rate and temperature. It shows that there are two main factors that can contribute to low friction in engine bearings; (i) low viscosity at low shear rate over the whole bearing temperature range of interest, which can be enabled a low viscosity base oil and a high VI and (ii) the ability to shear thin at the high shear rate conditions present in engine bearings.

Acknowledgements The authors would like to thank Repsol S.A. for supporting this work and supplying base fluids and additives.

Open Access This article is distributed under the terms of the Creative Commons Attribution 4.0 International License (http://creativeco mmons.org/licenses/by/4.0/), which permits unrestricted use, distribution, and reproduction in any medium, provided you give appropriate credit to the original author(s) and the source, provide a link to the Creative Commons license, and indicate if changes were made. 


\section{Appendix}

A finite difference-based, 3D thermal model was used to analyse the hydrodynamic and heat transfer behaviour of the lubricated bearing. This was based on iterative solution of (i) a 3D generalised Reynolds equation to determine flow and pressure in the oil film, (ii) the reduced Carreau Yasuda equation to determine viscosity at local shear rate and temperature, (iii) the energy equation to determine the temperature distribution in the oil film, (iv) the Laplace equation to determine the heat flux through the bearing shell and connecting rod holder.

Figure 19a shows the rotating bearing configuration at load $\mathrm{W}$, rotor surface speed, $u_{\mathrm{s}}$ and attitude angle $\psi$. In the model, the sleeve and connecting rod holder are treated as a single material cylinder. The position of thermocouple $\mathrm{A}$ is shown. Figure 19b shows the unwrapped bearing and coordinate system used.

\section{D Reynolds Equation}

The 3D generalised Reynolds equation was employed to model the hydrodynamic behaviour of the oil film [20]. This allows viscosity to vary with local temperature and shear rate both across the bearing and through the film thickness. It has the form

$\frac{\partial}{\partial x}\left(\rho J \frac{\partial p}{\partial x}\right)+\frac{\partial}{\partial y}\left(\rho J \frac{\partial p}{\partial y}\right)=u_{\mathrm{s}} \frac{\mathrm{d}}{\mathrm{d} x}\left(\rho J_{\mathrm{R}}\right)$,

where $J$ and $J_{\mathrm{R}}$ are given by

$J=\frac{J_{1 \mathrm{zh}} J_{\mathrm{o}}-J_{1} J_{\mathrm{ozh}}}{J_{\mathrm{o}}}, J_{\mathrm{R}}=\frac{J_{\mathrm{ozh}}}{J_{0}}, J_{0}=\int_{0}^{h} \frac{1}{\eta} \mathrm{d} z, J_{1}=\int_{0}^{h} \frac{z}{\eta} \mathrm{d} z$ $z$ is the distance through the film from the bearing surface; $\eta$ is the oil viscosity at $(x, y, z)$, and $\rho$ the oil density at $(x, y)$. For simplicity, density was allowed to vary with temperature across the film but not through the thickness, a valid approximation since the temperature variation through the film was always small. $J_{\text {ozh }}$ and $J_{1 \mathrm{zh}}$ are double integral expressions of the viscosity through the thickness of the film $h$ at each $(x, y)$ location given by

$J_{\text {ozh }}=\int_{o}^{h} J_{0 \mathrm{z}} \mathrm{d} z, J_{1 \mathrm{zh}}=\int_{o}^{h} J_{1 \mathrm{z}} \mathrm{d} z$

where $J_{0 z}=\int_{0}^{z} \frac{1}{\eta} \mathrm{d} z, J_{1 z}=\int_{0}^{z} \frac{z}{\eta} d z$.

Piezoviscous effects were taken to be negligible. Density was measured for all the test oils and decreased linearly with temperature:

$\rho_{T}=\rho_{60^{\circ} \mathrm{C}}+k(60-T)$.

$\rho_{60}{ }^{\circ} \mathrm{C}$ and $k$ varied slightly from oil to oil but were typically $830 \mathrm{~kg} / \mathrm{m}^{3}$ and 0.62 , respectively.

\section{Lubricant Shear Thinning}

The viscosity was determined at each $(x, y, z)$ location using the reduced Carreau-Yasuda equation:

$\eta=\eta_{\infty}+\left(\eta_{\mathrm{o}}-\eta_{\infty}\right)\left(1+\left(A_{\mathrm{r}} a_{\mathrm{T}} \dot{\gamma}\right)^{a_{\mathrm{r}}}\right)^{\left(\frac{n_{\mathrm{r}}-1}{a_{\mathrm{r}}}\right)}$,

where $\eta_{\mathrm{o}}$ is the first Newtonian viscosity; $\eta_{\infty}$ is the second Newtonian viscosity; $\dot{\gamma}$ is the shear rate; $a_{T}$ is a temperature dependent shift factor as defined by Eq. 2 and $n_{\mathrm{r}}, a_{\mathrm{r}}$ and $A_{\mathrm{r}}$ are reduced Carreau Yasuda fit constants (Table 2).

The first and second Newtonian viscosities were calculated as the low shear rate viscosities of the blend and of the
Fig. 19 a Bearing configuration under load and $\mathbf{b}$ unwrapped bearing and coordinate system. Gap shape is $h=c(1+\varepsilon \cos \theta)$, $\mathrm{d} h=-c \varepsilon \sin \theta \mathrm{d} \theta, x=R \theta$

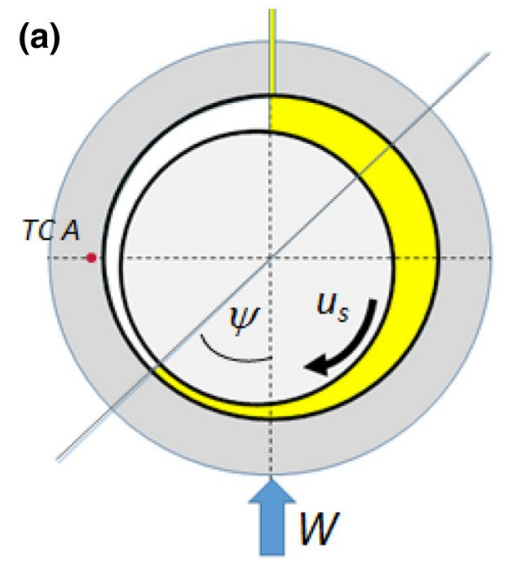

(b)
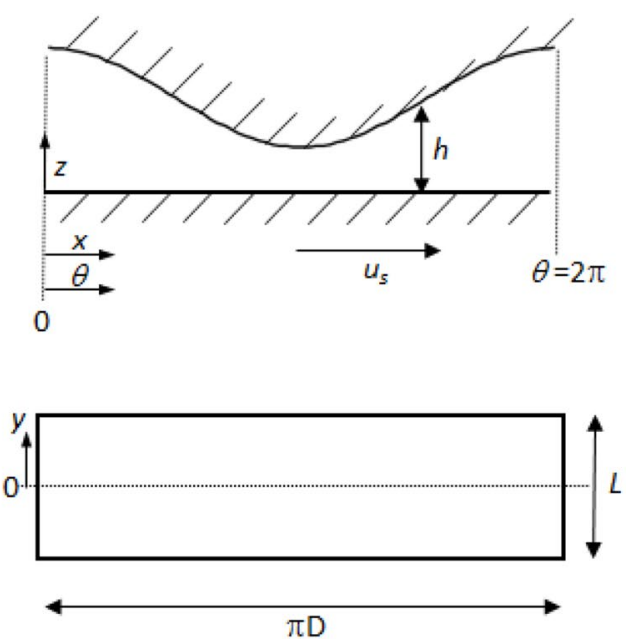
base oil respectively at temperature $\mathrm{T}$ using the Vogel equation with the constants $a_{\mathrm{o}}, b_{\mathrm{o}}$ and $c_{\mathrm{o}}$ from (Table 3):

$a_{0} e^{b_{\mathrm{o}} /\left(T-c_{\mathrm{o}}\right)}$.

The local shear rate was determined from the local velocity gradient:

$\dot{\gamma}=\left(\left(\frac{\partial u}{\partial z}\right)^{2}+\left(\frac{\partial v}{\partial z}\right)^{2}\right)^{0.5}$,

where

$\frac{\partial u}{\partial z}=\frac{u_{\mathrm{s}}}{J_{\mathrm{o}} \eta}+\frac{\partial p}{\partial x}\left(\frac{z}{\eta}-\frac{J_{1}}{J_{\mathrm{o}} \eta}\right)$ and $\frac{\partial v}{\partial z}=\frac{\partial p}{\partial y}\left(\frac{z}{\eta}-\frac{J_{1}}{J_{\mathrm{o}} \eta}\right)$.

Within the main Reynolds equation solution, Eqs. 11, 13 and 14 were solved iteratively at each location to establish a converged solution for the local viscosity; typically about 3 to 4 iterations were needed.

Equations 7 to 14 were solved iteratively to determine the fluid film pressure using central finite difference, with the boundary conditions $p=0$ at $x=0$ and at $y= \pm \mathrm{L} / 2$ and the conventional computing Reynolds exit boundary condition; if $p<0 p=0$, corresponding to $p=0, \mathrm{~d} p / \mathrm{d} x=0$.

After convergence, friction was determined as that acting on the rotating shaft from

$F=\int_{\text {full }} \tau_{x} \mathrm{~d} x \mathrm{~d} y$,

where $\tau_{x}$ the shear stress at the rotor wall. $\tau_{x}$ is given by

$\tau_{x}=\frac{u_{\mathrm{s}}}{J_{\mathrm{o}}}+\frac{\partial p}{\partial x}\left(h-\frac{J_{1}}{J_{\mathrm{o}}}\right)$.

The term "full" in Eq. 15 denotes the regions of the bearing that are locally full of oil. An issue in determining friction in journal bearings is whether the oil that passes through the minimum film region into the cavitation zone bridges the gap between the bearing and rotor to form cavitation streamers as shown schematically in Fig. 20, or whether it splits into separate coatings on the two surfaces. If the former, the streamers will substantially contribute to hydrodynamic friction. In this model,

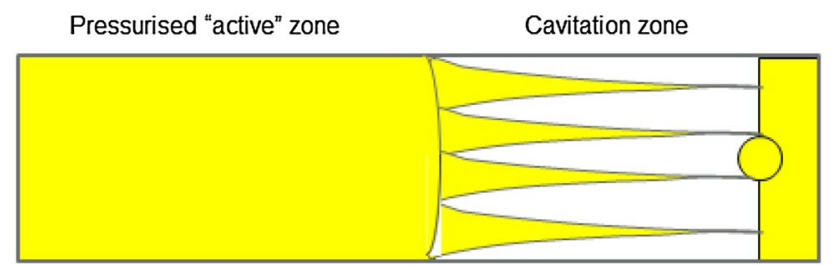

Fig. 20 Schematic diagram of regions of bearing that are full of oil both possibilities were explored and it was assumed that no oil was lost from the cavitated region by side-flow. Figure 20 also shows the oil supply port that has moved to bearing angle $-\psi$, where $\psi$ is the attitude angle adopted by the rotating shaft under load. The bearing was assumed to be filled with oil downstream of this port as shown and so as to contribute to Couette friction.

\section{Energy Equation; Oil Film Temperature}

The temperature distribution in the lubricant films was determined using the energy equation:

$\rho_{\text {oil }} C_{\text {oil }}\left(u \frac{\mathrm{d} T}{\mathrm{~d} x}+v \frac{\mathrm{d} T}{\mathrm{~d} y}-\left(\frac{z}{h} u \frac{\mathrm{d} h}{\mathrm{~d} x}\right) \frac{\mathrm{d} T}{\mathrm{~d} z}\right)=$

$K_{\text {oil }} \frac{\mathrm{d}^{2} T}{\mathrm{~d} z^{2}}+\eta\left(\left(\frac{\mathrm{d} u}{\mathrm{~d} z}\right)^{2}+\left(\frac{\mathrm{d} v}{\mathrm{~d} z}\right)^{2}\right)$

where $T$ is the local temperature in the film, and $\rho_{\text {oil }}, C_{\text {oil }}$ and $K_{\text {oil }}$ are the density, specific heat and thermal conductivity of the lubricant, respectively. Convection in the $z$ direction, and conduction in $\mathrm{x}$ and $\mathrm{y}$ directions were neglected $(\mathrm{d} T / \mathrm{d} z=0$, $\mathrm{d}^{2} T / \mathrm{d} x^{2}=0, \mathrm{~d}^{2} T / \mathrm{d} y^{2}=0$ ), as was compression heating. The left-hand term in Eq. 17 describes the convective heat transfer and the first on the right-hand side conduction, while the last expression is the energy dissipation due to shear. Within the first term, the $\mathrm{d} T / \mathrm{d} z$ expression allows for transformation from polar to flat coordinates [9]. This was included but in practice was negligible.

Equation 17 was solved using forward finite difference starting in the inlet supply position, determined from the attitude angle from the Reynolds solution as shown in Fig. 19. At this position, the temperature throughout the film was adjusted to allow for mixing with fresh oil at $T_{\text {supply }}$ to become

$T=\frac{T_{\text {cav }} Q_{\min }+T_{\text {supply }} Q_{\text {supply }}}{Q_{\text {min }}+Q_{\text {supply }}}$,

where $T_{\text {cav }}$ is the mean oil film temperature of oil in the cavitated zone when it reaches the supply port; $Q_{\min }$ is the oil flow in the cavitated zone and $Q_{\text {supply }}$ is the oil supplied at this position to fill the bearing. $Q_{\text {supply }}$ is $Q_{\mathrm{tot}}-Q_{\text {min }}$, where $Q_{\mathrm{tot}}$ is $u_{\text {sliding. }} . h_{1} . L / 2$ where $h_{1}$ is the gap at $\theta=0$ and $L$ is the bearing length. $Q_{\min }$ is the flow through the minimum film thickness region given by

$Q_{\text {min }}=2 \int_{0}^{L / 2}\left(\frac{\partial p}{\partial x} J_{\text {val }}+u_{\mathrm{s}} J_{\mathrm{R}}\right)_{\text {at } p \rightarrow 0} \mathrm{~d} y$.

Boundary conditions were that the oil film temperature at the bush and rotor interfaces were the same as those of the bush and rotor surface, respectively. 


\section{Laplace Equation; Bush Temperature}

Heat flow within the sleeve and connecting rod holder was calculated using the Laplace equation (Eq. 20), treating the combined sleeve and holder as simple cylindrical bush of one material.

$\frac{1}{r} \frac{\partial}{\partial r}\left(r \frac{\partial T}{\partial r}\right)+\frac{1}{r^{2}} \frac{\partial^{2} T}{\partial \theta^{2}}+\frac{\partial^{2} T}{\partial y^{2}}=0$.

This was solved using central finite difference with constant temperature gradient conditions across the oil/bush and bush/ air interfaces. The thermal gradient at the oil/bush interface was determined from continuity of heat flow:

$\dot{Q}^{\prime \prime}=k_{\mathrm{bush}}\left(\frac{\mathrm{d} T}{\mathrm{~d} y}\right)_{\text {bush/oil }}=k_{\text {oil }}\left(\frac{\mathrm{d} T}{\mathrm{~d} y}\right)_{\text {oil/bush }}$,

where $k_{\text {bush }}$ and $k_{\text {oil }}$ are the thermal conductivities of the bush and oil and the two temperature gradients are those within the bush and the oil respectively at the interface between the bush and the oil film.

The temperature gradient at the outer bush/air interface was determined by

$k_{\text {bush }}\left(\frac{\mathrm{d} T}{\mathrm{~d} y}\right)_{\text {bush/air }}=\alpha\left(T_{\text {bush/air }}-T_{\text {amb }}\right)_{\text {oil }}$,

where $\alpha$ is the heat transfer coefficient at the bush/air interface; $T_{\text {bush/air }}$ is the bush temperature at this interface and $T_{\mathrm{amb}}$ is the ambient temperature.

\section{Rotor Temperature}

The rotor was taken to have the same temperature throughout, as demonstrated by Dowson et al. [21]. The actual rotor temperature was assumed to be such as to result in no net into the rotor surface in contact with the oil [22], as shown in [23], where $A$ is the area of the oil/bush interface and $\phi$ is the local fraction of oil film (unity in the active zone and $<1$ in the cavitated zone). The alternative assumption of the rotor temperature being the same the mean bush surface temperature was also tested but gave similar temperature predictions.

$$
\int_{A} k_{\text {oil }} \emptyset\left(\frac{\mathrm{d} T}{\mathrm{~d} y}\right)_{\text {oil/bush }}=0 .
$$

\section{References}

1. Marx, N., Fernández, L., Barceló, F., Spikes, H.A.: Shear thinning and hydrodynamic friction of viscosity modifier-containing oils. Part 1: shear thinning behaviour. Tribol. Lett. 66, 92 (2018)

2. Marx, N., Fernández, L., Barceló, F., Spikes, H.A.: Shear thinning and hydrodynamic friction of viscosity modifier-containing oils. Part II: impact of shear thinning on journal bearing friction. Tribol. Lett. 66, 91 (2018)

3. Stambaugh, R.L., Kopko, R.J.: Behavior of non-Newtonian lubricants in high shear rate applications. SAE technical paper no. 730487 (1973)

4. Bell, J.C., Voisey, M.A.: Some relationships between the viscometric properties of motor oils and performance in European engines". SAE technical paper no. 770378 (1977)

5. Hamaguchi, H., Maeda, Y., Maeda, T.: Fuel efficient motor oil for Japanese passenger cars. SAE technical paper no. 810316 (1981)

6. De Carvalho, M.J.S., Seidl, P.R., Belchior, C.R.P., Sodré, J.R.: Lubricant viscosity and viscosity improver additive effects on diesel fuel economy. Tribol. Int. 43, 2298-2302 (2010)

7. Taylor, R.I., de Kraker, B.R.: Shear rates in engines and implications for lubricant design. Proc. Inst. Mech. Eng. Part J 231, 1106-1111 (2017)

8. Warrens, C., Jefferies, A.C., Mufti, R.A., Lamb, G.D., Guiducci, A.E., Smith, A.G.: Effect of oil rheology and chemistry on journal-bearing friction and wear. Proc. Inst. Mech. Eng., Part J 222, 441-450 (2008)

9. Ferron, J., Frene, J., Boncompain, R.: A study of the thermohydrodynamic performance of a plain journal bearing comparison between theory and experiments. Trans. ASME J. Lubr. Techn. 105, 422-428 (1983)

10. Allmaier, H., Priestner, C., Six, C., Priebsch, H.H., Forstner, C., Novotny-Farkas, F.: Predicting friction reliably and accurately in journal bearings - A systematic validation of simulation results with experimental measurements. Tribol. Int. 44, 1151-1160 (2011)

11. Allmaier, H., Priestner, C., Reich, F.M., Priebsch, H.H., Forstner, C., Novotny-Farkas, F.: Predicting friction reliably and accurately in journal bearings - the importance of extensive oil-models. Tribol. Int. 48, 93-101 (2012)

12. Allmaier, H., Priestner, C., Reich, F.M., Priebsch, H.H., NovotnyFarkas, F.: Predicting friction reliably and accurately in journal bearings- extending the EHD simulation model to TEHD. Tribol. Int. 58, 20-28 (2013)

13. Sander, D.E., Allmaier, H., Priebsch, H.H., Reich, F.M., Witt, M., Füllenbach, T., Skiadas, A., Brouwer, L., Schwarze, H.: Impact of high pressure and shear thinning on journal bearing friction. Tribol. Int. 81, 29-37 (2015)

14. Sander, D.E., Allmaier, H., Priebsch, H.H., Witt, M., Skiadas, A.: Simulation of journal bearing friction in severe mixed lubricationvalidation and effect of surface smoothing due to running-in. Tribol. Int. 96, 173-183 (2016)

15. Allmaier, H., Sander, D.E., Priebsch, H.H., Witt, M., Füllenbach, T., Skiadas, A.: Non-Newtonian and running-in wear effects in journal bearings operating under mixed lubrication. Proc. Inst. Mech. Eng., Part J 230, 135-142 (2016)

16. Yasuda, K.Y., Armstrong, R.C., Cohen, R.E.: Shear flow properties of concentrated solutions of linear and star branched polystyrenes. Rheol. Acta 20, 163-178 (1981)

17. Bird, R.B.: Dynamics of Polymeric Liquids: Fluid Mechanics, vol. 1. Chapter 3.6. 2nd edn. Wiley Interscience, New York (1987)

18. Engineering Sciences Data Unit No. 66023, Calculation Methods for Steadily Loaded, Pressure Fed Hydrodynamic Journal Bearings (1966) 
19. Seireg, A., Dandage, S.: Empirical design procedure for the thermohydrodynamic behavior of journal bearings. Trans. ASME J. Lubr. Technol. 104, 135-148 (1982)

20. Dowson, D.: A generalized Reynolds equation for fluid-film lubrication. Intern. J. of Mech. Sci. 4, 159-170 (1962)

21. Dowson, D.J.D.B.C.N., Hudson, J.D., Hunter, B., March, C.N.: Paper 3: An experimental investigation of the thermal equilibrium of steadily loaded journal bearings. In: Proceedings of the Institution of Mechanical Engineers, Conference Proceedings, vol. 181, pp. 70-80 (1966)

22. Stokes, M.J., Ettles, C.M.M.: A general evaluation method for the diabatic journal bearing. Proc. R. Soc. Lond. A 336(1606), 307-325 (1974) 